\title{
Social Unrest of Betawi's Traditional Arts and Culture Performers during COVID-19 Pandemic
}

\author{
Iwan Henry Wardhana ${ }^{1 *}$; Renny Nurhasana ${ }^{2}$ \\ ${ }^{1,2}$ School of Strategic and Global Studies, Universitas Indonesia \\ Jl. Salemba Raya No. 4, Jakarta 10430, Indonesia \\ 1iwanhwardhana3@gmail.com; ${ }^{2}$ rennynurhasana@yahoo.com
}

Received: $28^{\text {th }}$ October 2020/Revised: $23^{\text {rd }}$ November 2020/ Accepted: $25^{\text {th }}$ November 2020

\begin{abstract}
How to Cite: Wardhana, I. H., \& Nurhasana, R. (2020). Social unrest of Betawi's traditional arts and culture performers during COVID-19 pandemic. The Winners, 21(2), 107-112. https://doi.org/10.21512/tw.v21i2.6777
\end{abstract}

\begin{abstract}
The COVID-19 pandemic quarantine had caused social unrest in many sectors of society due to sudden downturn of economic activities as well as severe decrease of income. The research aimed to reduce social unrest among Betawi's traditional arts and culture performers, prevent unrest from rising to a greater level and preserve Betawi's traditional arts and culture in Jakarta. The social unrest data were collected by Jakarta Capital City Government, through Jakarta Culture Office via an intensive interview with Betawi's traditional arts and culture figures. The results of the interviews were identified and used as the basis for formulating policies that could reduce social unrest in the Betawi arts and cultural performers. The results show that Betawi's traditional art and culture performers' unrest can be overcome and prevented from escalating to the next level.
\end{abstract}

Keywords: Betawi traditional arts, culture performers, social unrest

\section{INTRODUCTION}

The COVID-19 pandemic has led many people to reduce gathering outside their homes. The imposition of social restrictions and territorial quarantine has caused social unrest in many sectors of society. The social unrest occurs since the economic activities have stopped or decreased suddenly which results in drastic income decreases. (Domínguez, Terceño \& Báez, 2019). The Betawi's traditional arts and culture performers which are under the auspices of the Jakarta Culture Office experience social unrest. Betawi's traditional arts and cultural activities have to be stopped during the pandemic and it resulted in the declining income of the performers. The Jakarta Capital City Government, through the Jakarta Culture
Office, has taken some steps to prevent the escalation of the social unrest. Through data processing obtained from intensive communication with the Betawi's traditional arts and culture performers, the Jakarta Culture Office took anticipatory steps to prevent social unrest from developing into action.

The level of social unrest begins with disappointment to a policy experienced by the community. These disillusioned performers move to the next level of organizing themselves to make their disappointment more audible. If the policymakers have not reacted to their disappointment at this level, then they will mobilize and eventually go to the highest level of taking action. (Jovanovic, Renn \& Schroter, 2019).

Previous research on pandemic situations has always focused on how to manage public health so as not to become infected. The research tries to manage the social side of the community that is affected not from the health concern but from the economic and social activities. One form of managing the impact of the economy and social activities is through measurable management of public policies.

The Jakarta Capital City Government, through the Jakarta Culture Office, which manages the Betawi's traditional arts and cultural performers, is studying this social unrest and making a series of public policies that will prevent this social unrest from escalating. Public policymaking is the formulation of a dynamic, complex, and interactive system in which public problems are identified and resolved by creating new public policies or by reforming existing public policies. Public problems can start anywhere, so this matter requires different policies at the local, national, or international levels. Public problems that affect public policymaking can be economic, social, or political (Sharkansky \& Hofferbert, 2018).

In the research, Jakarta Capital City 
Government, through the Jakarta Cultural Office, collects data through intensive communication in the form of in-depth interviews with Betawi's traditional arts and culture figures to find out their unrest during the COVID-19 pandemic. The results of the interviews are identified and used as the basis for formulating policies that could reduce social unrest in Betawi's traditional arts and cultural performers. The formulation of the policy can be a new policy or a renewed old policy. The policy is economic, social, and cultural within the scope of Betawi's traditional arts and cultural performers.

The policy will later reduce the level of social unrest and prevent social unrest from escalating to a greater level. Preventing social unrest from moving to a greater level means preventing greater handling costs that have to be carried out at a larger level (Jovanovic et al., 2019). Public policy is a series of activities carried out by the government to change their economy and society. In this case, the Jakarta Capital City Government is trying to manage public policy during the COVID-19 pandemic to change the economic decline in Betawi's traditional arts and cultural performers.

The research is carried out to reduce social unrest among Betawi's traditional arts and culture performers, prevent unrest from rising to a greater level and preserve Betawi's traditional arts and culture in Jakarta. It is in accordance with Governor Regulation No. 229 of 2016 concerning the Implementation of Betawi Cultural Preservation. The decrease in arts and cultural activities resulting in a drastic decrease in income has forced Betawi's traditional arts and culture performers to undertake other economic activities. If this goes on for a long time, a decrease in interest in the preservation of Betawi's traditional arts and culture can occur.

\section{METHODS}

Sustainability is an important concept in entrepreneurial crisis management which describes the organization's ability to continue to function throughout disruptive events (Doern, Williams \& Vorley, 2019). Besides, the conceptual aspect of sustainability also identifies which resources are affected by the crisis to be addressed during the crisis (Williams et al., 2017). Crisis management is one of the utmost importance during the COVID-19 crisis to promote sustainability. Crisis management is used to minimize the impact of a crisis and, if done well, it can quickly restore the functioning of an organization suffering from the effects of disruption or weakening of a system (Williams et al., 2017).

Researchers seek to identify steps that gradually lead to social unrest (Jovanovic et al., 2019). The research is to investigate which interventions or actions tend to increase or decrease social anxiety. The intervention can be a trigger to go up to a higher level or to fall to a lower level. Dropping to a lower level does not mean that the risk of social unrest will go away, but the possibility of escalation to a higher level is reduced. However, there is still the possibility that new events or decisions could re-enact the escalation process (Holdo \& Bengtsson, 2020).

Dissatisfied with their situation due to the need for solution, people will engage in public on an issue of social unrest. Dissatisfaction can arise for physical, social, or psychological reasons. If someone feels dissatisfied with a policy, that dissatisfaction tends to be displayed in a public arena. Such activities can be carried out spontaneously without communication for plans with others having similar experiences.

This community group is the performers of Betawi's traditional arts and culture in Jakarta who are being affected by the policy of social restrictions and territorial quarantine. To identify their social unrest, the Jakarta Culture Office collects data through interviews with these performers. Most of the policy initiatives are taken to protect the economy during the COVID-19 crisis by targeting established groups to protect jobs and the continuation of their economic activities (Kuckertz et al., 2020).

An interview is a meeting between two people to exchange information and ideas through question and answer so that meaning can be constructed in a particular topic (Jovanovic et al., 2019). The interview is also a tool to double-check or prove information or information previously obtained and is also a direct communication technique between researchers and respondents. The interview is a qualitative research technique that allows for interpersonal discussions. This will increase insight into the thoughts, feelings, and behavior of both the interviewer and the interviewee. Interviews are usually conducted to reveal important phenomena or issues.

The structure of the interview can range from unstructured to structured. Qualitative research generally uses unstructured or semi-structured interviews (Jovanovic et al., 2019). Unstructured interviews start with general questions in a wide area of research. The interview is usually followed by a keyword, agenda or a list of topics to be covered in the interview. However, none of the questions are predetermined except in very preliminary interviews. Semi-structured interviews start with the issues covered in the interview guide. An interview guide is not as timetable as in quantitative research. The question sequence is not the same for each participant depending on the interview process and the answers of each individual.

Robinson (2000) states that in-depth, formal open interviews are the mainstream of qualitative research. A formal qualitative interview is an unstructured conversation to prioritize recording and transcribe verbatim (word for word) data, and the use of an interview guide instead of a rigid set of questions. The interview guide consists of a set of general questions or a topic chart and is used at the start of the meeting to provide structure. The general rule in qualitative interviews is not to impose an agenda or 
framework on participants, rather the purpose of this interview is to follow the wishes of the participants. The use of this format is to capture participants' perspectives following the research objectives (Mei, 2020).

According to Moleong (2017) in-depth interviews are a process of digging deep, open, and free information with problems and research focus and directed at the research center. In this case, the in-depth interview method is carried out with a list of questions that have been prepared in advance. The general purpose of in-depth interviews is to dig deeper into the general habits of the group being the research target and the reasons behind them. It is possible because indepth interviews are flexible so that researchers can ask further questions.

The interview is part of a qualitative method, in which there is an in-depth interview technique. It is the process of obtaining information for research purposes using face-to-face question and answer between the interviewer and the respondent, with or without using an interview guide where the interviewer and informants are involved in a relatively long social life. The special feature or peculiarity of this in-depth interview is its involvement in the respondent's life.

In in-depth interviews, information is extracted in-depth on a predetermined topic (based on the purpose of the interview) using open questions. The excavation was carried out to find out their opinion based on the respondents' perspective in looking at a problem. The interview technique is carried out by an interviewer by interviewing one person face to face. (Walensky \& del Rio, 2020) The researchers invite the figures from Betawi's traditional arts and culture performers to have an in-depth conversation about the situation in Betawi's traditional arts and culture performers in exhibiting their traditional cultural arts performances in COVID-19 pandemic.

The benefits of conducting in-depth interviews are: (1) The discussion topic of the issues asked can be complex or very sensitive; (2) Complete and indepth information about the respondent's attitudes, knowledge, and views of the problem can be obtained properly; (3) Anyone can get the opportunity to be interviewed but based on the purpose of the research.; (4) Respondents can freely answer the questions asked without pressure from others or embarrassment in expressing their opinions; (5) Interviews can use guidelines or without using guidelines. If guidelines are used, the flow of questions that have been made does not have to be done in order but depends on the needs of the field.

An in-depth interview is a focused discussion between the researcher and the respondent regarding the research issues. In the discussion, the researcher must be able to control himself, so that he does not stray far from the subject matter. The type of question used in the in-depth interview technique is an open question. Compared to closed questions, the open question has some advantages such as, for example, allowing various answers to be obtained according to the respondent's thinking. Therefore, in conducting indepth interviews, the questions cannot be formulated with certainty in advance, but these questions will depend a lot on the ability and experience of the researcher to develop follow-up questions based on the respondent's answers.

\section{RESULTS AND DISCUSSIONS}

The interview consists of three stages. The first stage is the introduction to build a trusting relationship. The second stage is the most important because useful data will be obtained. The final stage is to draw summary of participant responses and confirmation or any additional information. The first Betawi's traditional arts figure is Ridwan Saidi, a former member of the People's Representative Council and a Betawi cultural observer who is a graduate of the Faculty of Social and Political Sciences (FISIP), University of Indonesia. He became a member of the People's Representative Council through the United Development Party (PPP) in 1977-1987. As a Betawi cultural observer, Ridwan is heavily involved in cultural preservation activities as well as writing books about the Betawi people.

The second traditional arts figure is Atien Kisam, a Betawi artist who has worked in the world of traditional Betawi's traditional art and culture for a long time. On the sidelines of his busy life, the man who was born with the name Muhammad Supriyatin is active as a teacher of traditional Betawi dance called Tari topeng Betawi. The third Betawi's traditional art figure is JJ Rizal, a historian, writer, and founder of the Bamboo Community publishing which has published many books on the themes of history, culture, and humanities. He studied at the Department of History at the Faculty of Letters, University of Indonesia and graduated in 1998. He received a Cultural Award from the Governor of DKI Jakarta in 2009. His writing about Junghuhn in National Geographic Indonesia was voted "The Best International 2010" by National Geographic International Magazine.

All the Betawi's traditional art and culture figures are invited to have an interview individually in Jakarta Culture Office. The interview is a formal lunch invitation starting from 10:00 AM to 15:00 AM and it has a one-hour lunch break. Four main questions would be asked to the interviewee in an unstructured in-depth interview in random order depending on the flow of the conversation carried by the interviewers. The four main questions are to seek: (1) The interviewee's opinion on the Jakarta Capital City Government policy on the COVID-19 situation; (2) How the policy gives impact to Betawi's art and culture performers; (3) How the performers handle the situation; (4) The interviewee's expectation of Jakarta Culture Office. The interview would be voicerecorded, and the interviewees are not aware of the objectives of the interview.

Ridwan Saidi, Atien Kisam, and JJ Rizal point out that the imposition of social restrictions and 
territorial quarantine that has caused social unrest in the Betawi arts and culture performers in Jakarta. The social restriction and territorial quarantine have made the Betawi's traditional art and cultural exhibition is prohibited, which leads to the income decline to the performers. However, social restriction and territorial quarantine are the proper policies that must be taken by the Jakarta City Government to tackle the spread of COVID-19.

They also think that since the people should make a social restriction and territorial quarantine, the performers encounter a sudden prohibition for their art and culture performances and a sudden decrease in demand for performances. This is more than a pandemic problem as the consequences deliver an economical, social, and cultural obstruction to the performers. Therefore, social restriction and territorial quarantine should be accompanied by a new policy that provides supporting facilities for Betawi's traditional art and culture performers. Ridwan Saidi, Atien Kisam, and JJ Rizal have different points in exposing the supporting facilities needed by Betawi's art and culture performers.

Ridwan Saidi says that some of the performers may have another source of income by becoming a temporary ojek (taxi bike) driver but this line of business also experiences a decrease in demand. Some others rely on the room-renting business that also experiences a decrease in demand. It is happening not only to the Betawi's art and culture performers, but also to all people in Jakarta, which need assistance from the government. However, as the performers have the Jakarta Culture Office as a stakeholder for the preservation of Betawi culture, it is only natural for them to ask for support from the Jakarta Culture Office. The assistance would be on fundraising to support the economy of the Betawi's traditional art and culture performers during this social restriction and territorial quarantine.

Atien Kisam says that many Betawi's traditional art and culture performers should practice their skills despite no demand for their performance. In this case, they need to do virtual practice with other performers through an online application or in an actual rehearsal room with certain health protocols. Atien Kisam proposes an idea that Jakarta Culture Office can provide the facilities for organizing either virtual or actual practice for Betawi's traditional art and culture performances. When this is facilitated, the greater action may come to follow, such as a virtual performance through an online application with an admission ticket or actual performance with a certain health protocol applied.

JJ Rizal exposes how Betawi's traditional art and culture performers could make a charity performance on local television. The charity performance would be weekly until the policy of social restriction and territorial quarantine is lifted. The viewers could donate to a certain bank account that is mentioned by the local television. These weekly performances are then resonated through social media of Betawi's celebrities. The performances is considered be easier with the assistance of Jakarta Culture Office in providing the networking to the local television and social media of Betawi's celebrities.

From the answers of Betawi's figures, it can be identified that the policy of social restriction and regional quarantine is the right policy in dealing with the spread of COVID-19 in Jakarta. The policy causes social unrest in the community, including Betawi's traditional arts and culture performers. To anticipate social unrest from this policy, new or updated policies are needed to be adapted by the performers. In introducing policies to anticipate social unrest, comprehensive socialization is needed both from policymakers and policy recipients.

Overall dissemination to policymakers is carried out as a process of formulating steps to be taken to policy recipients. It is like a planning consolidation that will keep a plan going. Policymakers will carry out socialization to policy recipients by implementing the steps that have been formulated.

Based on the in-depth interview, Jakarta Culture Office will formulate several policies to accommodate the unrest factors in Betawi's traditional art and culture performers during the COVID-19 pandemic. The formulation begins from the classification of the four questions from the interview. Each question would lead the researcher to acknowledge the situation better so the policy would be more accurate to the needs of Betawi's traditional art and culture performers.

Public policy is what the government wants to do to achieve certain goals. This means that a mere statement of intention, desire, principle, or expression of desire cannot be called a public policy. Public policies must mean allocating tangible resources through projects and programs designed to respond to public problems and challenges that require solutions in the form of government action. This means that there is a real pattern of resource allocation from projects and programs designed to respond to public demands, in this case, Betawi's arts and culture performers.

The first question gives feedback on how the policy of social restriction and territorial quarantine is the right decision to tackle the spread of COVID-19. However, the policy would make an impact on the social, economic, and cultural life of the people especially the Betawi's traditional art and culture performers. This impact needs to be handled by making a new, or modify, policy to accommodate the needs of Betawi's traditional art and culture performers. All performers accept the social restriction and territorial quarantine but expect more assistance from Jakarta Culture Office on the consequences.

The researchers also learn the condition of Betawi's traditional art and culture performers in dealing with the COVID-19 situation through the second and third questions. The performers need assistance at once to escape the consequences of social restriction and territorial quarantine. The sudden decline of income and the suddenly alter profession may lead to a new level of stress. This does not include 
the decline in interest in the preservation of Betawi's traditional arts and culture because they have to carry out other activities to fulfill their daily needs.

From the fourth question, the researchers learn that Betawi's traditional art and culture performers need assistance on the fundraising, virtual and actual practicing as well as performance. The fundraising would be started by making a list of Betawi's traditional art and culture performers in Jakarta. The list is created by inquiring the performers to input their data on a certain link in a time. The list is then checked by the local district head to make sure that the validation of the data obtained. All names on the list that has been validated would receive a certain amount of fund every month.

From the four questions, it is acknowledged that the unrest has been formed and it need to be solved before it can escalate to the next level. The unrest lies on the economic and art performance aspects. It means the policy has to be created to accommodate the economic and art performance aspects to prevent the escalation of the unrest. The policy should include fundraising, virtual and actual practices and performances.

Virtual training is carried out through an online application on an individual device owned by each trainee and trainer of Betawi's traditional arts and cultural activities. Each trainer and trainee are in their respective residences with their respective devices to meet via online application. Meanwhile, the actual training is carried out in a large room or open space with strict health protocols. Trainees and trainers come to a designated place to do the exercise. The place specified can be a closed or open space. The length of both practices is determined by the trainers and the performances' needs.

Betawi's traditional art and culture performers are given information knowledge about virtual practices which include introduction of the online tools and devices, how to use the tool and devices, and the provision of excellent internet connection to them. The training will be held in their local district starting from how to use the tool and devices to make virtual practices. They will receive monthly internet connection quotas to support the virtual activities. The length of the virtual practices would be at the decision of the show director. After that, they will conduct three actual practices prior their performance. The actual practice would be done in a large room with a strict health protocol.

Virtual performance is the performance of a Betawi's traditional art and culture through an online application or local television. The performance is recorded in a video and then broadcast on an online application or local television. Video recording for virtual performance takes place in a certain closed or open place with strict health protocols and without audience.

The actual performance is the performance of Betawi's traditional art and culture in a closed room or open space in the presence of the audience. The committee, participants, and audiences who attend will go through strict health protocols. Audiences' seating and player positions are tailored to accommodate health protocols. The number of audiences who attend is limited and the performance could take place within a few days of the performances.

After they have done their virtual and actual practices, they have to perform. The actual performance would be held in a large room or an open room like an amphitheater with an audience in a strict health protocol. The actual performance would be a charity show or a free show depending on the situation.

Meanwhile in virtual performance, the performers are doing the show in a large room with a strict health protocol without the audience, which will be broadcast live or recorded at the Jakarta Culture Office website or social media platform, or on local television. The virtual performance would be a charity show or a free show depending on the situation. The performers will be paid by Jakarta Culture Office, and the charity will be funneled to the performers.

\section{CONCLUSIONS}

The public policy reflects the demands of the masses and the values of the executive elite. The public policy change will be incremental rather than revolutionary. Gradual change allows a response to events that threaten the social system, with minimum system change or dislocation. The assumption presupposes that if the government is committed to serving the interests of the masses, it must do something to reduce elite excess. This can be done by adopting a participatory approach to policymaking, involving all key stakeholders, thereby reducing undue manipulation of elites.

Evidence-based policymaking has never been this big. Increased data availability, investment in research, and a greater public focus have given policymakers a broader ability to determine whether the public investment achieves the desired results based on information in evaluating social costs and benefits. Evidence-based policies and practices can lead to better use of taxpayers' money and better outcomes for children, adults, and families.

Evidence-based policymaking can take many forms, such as using research findings to inform new policies or improve the effectiveness of existing programs, supporting data collection and analysis for research and management, developing policies that encourage the use of evidence, and so forth. It is most applied to social service and humanitarian programs, but a variety of government programs can benefit from gathering data and using evidence.

Evidence-based policies have encouraged careful analysis of service programs and policy selection to improve the quality of decision making. Careful research findings are useful and necessary input for policymakers in considering policy sustainability through program development and review. 
An in-depth interview is a great tool in creating an accurate policy to anticipate the unrest of Betawi's traditional art and culture performers. Policies must be very accurate to prevent social unrest from escalating to higher levels and becoming more difficult to handle. A good policy is a research-based policy, where policymakers collect accurate data about social unrest in their environment. Based on the in-depth interviews, researchers make policies that can accommodate the performers' unrest.

By carrying out evidence-based policies regarding social unrest that arising in Betawi's traditional art and culture performers, public policies can be decided by accommodating their wishes. It makes the performers feel their existence is wellpreserved. In the end, the performers will also pay more attention to the preservation of Betawi's traditional arts and culture in Jakarta.

The performers' unrest can be overcome and prevented from escalating to the next level. The research is the beginning of a research-based policy culture among the policymakers. The research is the beginning of a research-based policy culture among the policymakers. The research-based policy will not end here as new unrest will emerge, and anticipation at the lowest level must be done immediately to prevent the unrest from escalating. Not to mention in-depth interviews should always be conducted when new social unrest occurs.

\section{REFERENCES}

Doern, R., Williams, N., \& Vorley, T. (2019). Special issue on entrepreneurship and crises: business as usual? An introduction and review of the literature, Entrepreneurship \& Regional Development, 31(56), 400-412, https://doi.org/10.1080/08985626.201 8.1541590 .

Domínguez, D. C., Terceño, J. R., \& Báez, A. B. (2019). El malestar social a través de las nuevas tecnologías: Twitter como herramienta política. Revista Latina de Comunicación Social, 74(10), 1264-1290. https:// doi.org/10.4185/RLCS-2019-1383.
Holdo, M. \& Bengtsson, B. (2020). Marginalization and riots: A rationalistic explanation of urban unrest. Housing, Theory, and Society, 37(2), 162-179, https://doi.org/10.1080/14036096.2019.1578996.

Jovanovic, A., Schröter, R., \& Renn, O. (2019). Social unrest: A systemic risk perspective. GRF Davos Planet@ Risk, 2(2), 125-134. https://www.researchgate.net/ publication/261795249_Social_unrest_a_systemic_ risk_perspective.

Kuckertz, A., Brändle, L., Gaudig, A., Hinderer, S., Reyes, C. A. M., Prochotta, A., Steinbrink, K., \& Berger, E. S. (2020). Startups in times of crisis-A rapid response to the COVID-19 pandemic. Journal of Business Venturing Insights, 13, 1-13. https://doi. org/10.1016/j.jbvi.2020.e00169.

Mei, C. (2020) Policy style, consistency and the effectiveness of the policy mix in China's fight against COVID-19. Policy and Society, 39(3), 309-325. https://doi.org/1 0.1080/14494035.2020.1787627.

Moleong, L. J. (2017). Metodologi Penelitian Kualitatif (Edisi Revisi). Bandung: PT Remaja Rosdakarya.

Robinson, J. P. (2000). Phases of the qualitative research interview with institutionalized elderly individuals. Journal of gerontological nursing, 26(11), 17-23. https://doi.org/10.3928/0098-9134-20001101-06.

Sharkansky, I. \& Hofferbert, R. (2018). Dimensions of State Politics, Economics, and Public Policy. The American Political Science Review, 63(3), 867-879. https://doi.org/10.2307/1954433.

Walensky, R. P. \& del Rio, C. (2020) From mitigation to containment of the COVID-19 pandemic: Putting the SARS-CoV-2 genie back in the bottle. JAMA, 323(19), 1889-1890. https://doi.org/10.1001/ jama.2020.6572.

Williams, T. A., Gruber, D. A., Sutcliffe, K. M., Shepherd, D. A., \& Zhao, E. Y. (2017). Organizational response to adversity: Fusing crisis management and resilience research streams. Academy of Management Annals, 11(2), 733-769, https://doi.org/10.5465/ annals.2015.0134. 